Pecvnia, 9 (2009), pp. 285-318

\title{
La financiación por medio de Acciones Privilegiadas. Una reflexión sobre su aplicación en algunas empresas ferroviarias españolas durante el siglo $\mathbf{X X}$
}

Recibido: Noviembre 2009 Aceptado: Enero 2010

\author{
Miguel Ángel Villacorta Hernández \\ mianvi@emp.ucm.es \\ Universidad Complutense de Madrid \\ Economía Financiera y Contabilidad II \\ Avenida Filipinas, 3 \\ 28003 Madrid (España)
}

Históricamente, las empresas ferroviarias españolas se financiaron por medio de empréstitos, en menor medida mediante acciones ordinarias $y$, de forma casi testimonial, con híbridos financieros. Esta investigación pretende detallar las posibles ventajas que hubiera supuesto, para estas compañías, la financiación por medio de clases de acciones y otros híbridos financieros.

Palabras clave: Acciones privilegiadas, empresas ferroviarias, híbridos financieros.
Historically, the Spanish railway companies were financed through borrowing, to a lesser degree by stock and, almost testimonial with hybrid financing. This research aims to describe the potential benefits that would have led, to these companies, financing through class actions and other financial hybrids.

Key words: preference shares, railway companies, financial hybrids. 


\section{INTRODUCCIÓN}

Los recursos de las sociedades ferroviarias han sido adquiridos, fundamentalmente, por tres procedimientos: la financiación obtenida por el desarrollo de la actividad empresarial, la financiación bancaria y la derivada de emisiones normalizadas realizadas por ellas mismas.

Las empresas ferroviarias españolas se han financiado por todas ellas, si bien, cuando han utilizado emisiones normalizadas, mayoritariamente lo han llevado a cabo por medio de empréstitos, utilizando en mucha menor medida las acciones ordinarias ${ }^{1} \mathrm{y}$, de forma casi testimonial, los híbridos financieros.

Los híbridos financieros son el conjunto de emisiones normalizadas diferentes de las acciones ordinarias y de los empréstitos. Por un lado, son ejemplos de híbridos financieros los diferentes tipos de obligaciones con alguna característica de las acciones como las convertibles o indexadas ${ }^{2}$. Por otro lado, también son ejemplos de híbridos financieros las clases de acciones, entre las que se encuentran las acciones privilegiadas, las acciones preferentes, las acciones sin voto y las acciones rescatables.

Esta investigación pretende detallar las posibles ventajas que hubiera supuesto, para estas compañías, la financiación por medio de clases de acciones.

\section{HÍBRIDOS FINANCIEROS}

La innovación financiera ha producido un elevado número de productos financieros. De entre todos los medios de innovación financiera, son especialmente relevantes los "híbridos" (hybrid securities,

\footnotetext{
La financiación de las empresas ferroviarias españolas es realizada fundamentalmente por empréstitos, siendo mucho menos importante la financiación por medio de acciones, como ha demostrado el historiador Pedro Tedde (1978: 9-354).

2 Al igual que ocurre con la financiación con acciones, también existen diferencias territoriales en la financiación con empréstitos de las empresas ferroviarias. En la Europa continental, normalmente existe un único modelo de obligaciones, bien sea de carácter personal o general, como en Francia, bien de carácter hipotecario, como en España (aunque la Compañía T.B.F se financió por obligaciones hipotecarias y no hipotecarias). En Estados Unidos, casi todas las compañías ferroviarias están financiadas por cuatro tipos de empréstitos: obligaciones hipotecarias, obligaciones diversas, obligaciones cuyo seguro radica únicamente en el beneficio líquido y obligaciones cuya garantía única es el material móvil de las compañías (Maristany 1906: 56).
} 
hybrid Finanzierungsinstrumente, valeurs mobilières hybrides, strumenti finanziari, ibridi/partecipativi), denominación concedida tradicionalmente a los activos financieros generados en una posición financiera intermedia entre deuda y acción (Mourgues 1996; Engel, Erickson y Maydew 1999: 249-274; Lamandini 2001; Pisano 2003: 1.268-1.315).

El mercado financiero muestra una clara tendencia al acercamiento entre la emisión de deuda y la participación en fondos propios, sin duda para aprovechar las ventajas de la otra categoría ${ }^{3}$, intentando ser más atractiva para la posible elección como inversión. Esa permeabilidad opera en la mayoría de los niveles de distinción, permitiendo encontrar una aproximación en las características de la retribución y duración del derecho, produciendo un debilitamiento de la frontera que separa los tradicionales conceptos de acción y deuda. No es la única forma de innovación financiera, pero gran parte de los productos que origina pueden englobarse dentro de una mezcla de las dos figuras clásicas de inversión a largo plazo.

Las obligaciones perpetuas, participativas y convertibles son empréstitos que incorporan aspectos básicos de las acciones. Las acciones sin voto, privilegiadas, rescatables y las preferentes son fondos propios en los que se pueden intuir características de una emisión de obligaciones.

Esta investigación analiza las emisiones de acciones, diferentes de las acciones ordinarias, realizadas por las empresas españolas relacionadas con el ferrocarril.

En el ámbito internacional, las acciones privilegiadas se caracterizan por la utilización de una gran diversidad de nomenclaturas. La práctica mercantil española y la doctrina se une a la variedad terminológica utilizando varios términos para denominar figuras similares, sin diferenciarlos claramente: privilegiadas, preferentes, especiales y clases de acciones ${ }^{4}$. La terminología de acciones preferentes o privilegiadas es la más extendida en la práctica comercial española, sin duda como consecuencia de la traducción directa de los ordenamientos más cercanos al

3 Todo esto ha permitido afirmar que la financiación con híbridos financieros "(...) tiene su origen en la diversificación financiera" (Howells y Bain 2002: 487).

4 La variedad terminológica en las empresas ferroviarias es aun más acusada. Por ejemplo, la "Entre Rios Raylways" argentina posee "(...) acciones privilegiadas de 5\%, así como del $4 \%$ de la segunda categoría". La "Gran Truck Railway of Canada" posee "(...) acciones privilegiadas de primer grado (...) y de segundo grado" (Revista de Obras Públicas 1906). 
nuestro: vorzugsaktien (Alemania), azioni preferenciali (Italia), preferred shares (Reino Unido) ${ }^{5}$ o preferred stocks (Estados Unidos). Frente a todas las denominaciones anteriores, la legislación mercantil española sólo utiliza dos términos: acciones privilegiadas ${ }^{6}$ y clases de acciones ${ }^{7}$.

El punto de partida de esta investigación es la constatación de las diferencias de financiación entre los distintos territorios a lo largo del siglo XX. Las empresas ferroviarias estadounidenses y británicas están financiadas al $50 \%$ entre acciones y empréstitos, mientras que las sociedades de la Europa continental están financiadas mucho más por obligaciones que por acciones (Maristany 1906: 55). Además, y más importante para esta investigación, también hay diferencias dentro de la estructura del capital. El capital social de las empresas ferroviarias en Estados Unidos y el Reino Unido está compuesto por acciones ordinarias y privilegiadas, mientras que el capital en la Europa continental está formado por acciones ordinarias en casi todos los casos (Maristany 1906: 55) ${ }^{8}$.

5 Además de la denominación preferred shares, utilizada en la legislación mercantil británica tradicionalmente, en Companies Act 2006 también se utiliza el concepto clases de acciones (Classes of shares). Cfr. Chapter 9, "Classes of Shares and Class Rights", Introductory, s. 629 Classes of Shares: "For the purposes of the Companies Acts shares are of one class if the rights attached to them are in all respects uniform. For this purpose the rights attached to shares are not regarded as different from those attached to other shares by reason only that they do not carry the same rights to dividends in the twelve months immediately following their allotment".

6 El artículo 50.1 del Texto Refundido de la Ley de Sociedades Anónimas (TRLSA) regula la emisión de acciones privilegiadas, entendidas como las que confieren unos derechos de mayor categoría respecto a las ordinarias.

7 El artículo 49 del TRLSA define el concepto de clases de acciones como "(...) el conjunto de acciones de una sociedad que comparten los mismos derechos, siendo a su vez diferentes a los derechos de otras clases de acciones, ya sea por incluir más derechos, menos derechos o por la inclusión de algunos y la exclusión de otros". En nuestra opinión, la diferenciación de emisiones en clases de acciones, aunque menos utilizada en el mercado financiero, es la terminología adecuada. No parece conveniente denominar acciones privilegiadas a las clases de acciones con mayor número de derechos respecto a una clase existente, ya que si posteriormente se realiza una nueva emisión, el privilegio de la anterior emisión podría ser ahora un derecho inferior frente a la nueva. Además, no en todos los casos resulta fácil a un observador decidir cuándo se encuentra ante acciones privilegiadas en términos absolutos o ante emisiones con una ventaja en un derecho y una desventaja en otro. Por ejemplo, las acciones sin voto constituyen una clase de acciones, incluso podrían denominarse acciones especiales si se acepta a otra emisión de acciones previa como ordinaria, pero difícilmente podría entenderse como acciones privilegiadas o preferentes, pues las ventajas económicas son ensombrecidas por la pérdida de voto. Por esta razón, parece más conveniente hablar de emisiones especiales en vez de privilegiadas o preferentes $\mathrm{y}$, aun mejor, de diferentes clases de acciones. El término clases de acciones sólo requiere que dos emisiones tengan derechos diferentes, en contraposición a la consideración de privilegiadas o preferentes, que precisa considerar a una de las emisiones como ordinaria o normal.

8 La importancia de la opinión de Maristany se deriva de que fue Director General de varias empresas, entre ellas MZA, y realizó un viaje a Estados Unidos, a partir del cual empezó a escribir sobre las diferencias del sector ferroviario español y estadounidense. 


\section{INTERNACIONALES}

\section{ACCIONES PRIVILEGIADAS EN EMPRESAS FERROVIARIAS}

Las primeras acciones privilegiadas aparecieron en el año 1639 en Holanda (Gasperoni 1950: 162). Por su parte, las primeras acciones privilegiadas de gran importe fueron emitidas por los cartels y trusts estadounidenses.

Es posible realizar un análisis detallado de las posibilidades de creación de clases de acciones conferidas por cada legislación a lo largo de la historia, para observar la fuerte relación entre la emisión de estos títulos y la financiación de las empresas ferroviarias, sobre todo en Estados Unidos y Alemania. Para realizar este estudio, y buscar rasgos homogéneos, hemos dividido los diferentes mercados y legislaciones mercantiles en las tres principales áreas de influencia9: anglosajona, germánica y latina ${ }^{10}$.

\subsection{Derecho anglosajón}

El Derecho anglosajón tiene su máximo exponente en las legislaciones del Reino Unido y Estados Unidos.

El Derecho positivo de las sociedades por acciones de los países anglosajones está caracterizado por la preminencia de las normas de derecho facultativo (default) sobre las de derecho imperativo. Esto provoca "(...) un sistema abierto de clases de acciones" (Campuzano 2000: 69) de forma que la autonomía estatutaria dispone de un ámbito de

9 Hemos diferenciado el estudio de las clases de acciones en tres bloques, porque es la agrupación adecuada del conjunto de Derechos societarios internacionales. Los países anglosajones están dominados por la "concepción contractualista" del Derecho de sociedades por acciones, en la que las normas imperativas han dado paso a la concepción dispositiva (default) del Derecho de sociedades por acciones, donde posee gran importancia el corporate governance. Por su parte, los países de la Europa continental mantienen la "concepción institucionalista" de la sociedad por acciones, fundamentada en una visión imperativa del Derecho de sociedades por acciones (Kübler 1998: 54; Mattei 2003: 616-617; Peñas 2007: 240; 2008: 123-162).

10 Dentro de la concepción institucionalista de la sociedad anónima es posible diferenciar entre el modelo germánico y el latino. La sociedad anónima de este último sistema se ha caracterizado por ser una forma social que, aunque ha tomado como modelo inicial de referencia el de la gran empresa, se ha caracterizado por una flexibilidad tal que ha permitido también el uso habitual de dicha forma social por parte de empresas de mediano o incluso pequeño tamaño. Por el contrario, la sociedad por acciones germánica, es una forma jurídica en la que el principio de autonomía de la voluntad ha tenido un ámbito de actuación escaso. La vigente Ley de Sociedades Anónimas, establece que los estatutos sociales sólo pueden apartarse de las normas contenidas en dicha Ley cuando expresamente lo admita la propia norma legal (art. 23.5 Aktiengesellschaft de 6 de septiembre de 1965), y como esto ocurre en muy pocas ocasiones, el resultado es una regulación muy rígida (Kübler 1998: 54; Mattei 2003: 616-617; Peñas 2008: 123-162). 
actuación amplio para que el emisor cree un producto financiero atractivo para los inversores.

Las acciones privilegiadas son conocidas en el Derecho británico "(...) desde principios del siglo XVII, aunque su generalización en la práctica se produce a lo largo de los siglos XVIII y XIX" (Gower's 1997: 23).

En un primer momento, prevalece entre las empresas británicas la emisión de acciones de una única clase, de alto valor nominal. Esta tendencia varía a principios del siglo XIX, al aumentar el número de pequeños accionistas que invierten en la sociedad pero que no desean participar en su gestión. La generalización de las clases de acciones se va a producir en el doble ámbito de los derechos de socio; no sólo se introducen diferencias en el plano de los derechos económicos, sino también con relación al derecho de voto que no se configura con carácter esencial. Se emiten así acciones preferentes, con valor nominal menor, capaces de satisfacer simultáneamente las necesidades de accionistas centrados en la obtención de un rendimiento fijo, y de sociedades intentando aumentar capital sin el riesgo de una pérdida de control por parte de los accionistas existentes. De acuerdo con esta nueva orientación, a partir de 1830 determinadas sociedades incorporan en sus estatutos la posibilidad de poder emitir tanto acciones preferentes como ordinarias.

Entre los sectores que utilizan masivamente acciones privilegiadas (preferred stock) destacan las compañías ferroviarias, de tal forma que "(...) en 1849 el 66\% del capital social total de las compañías de ferrocarril británicas adoptaba la forma de preferred stock" (Kindleberger 1993: 194).

La creación de clases de acciones es contemplada expresamente en la Ley de 21 de diciembre de 1908. A estos efectos, la Ley distingue entre tres figuras:

1) Acciones privilegiadas (preferred shares), caracterizadas por poseer un mayor derecho al dividendo, un derecho al reembolso anticipado o un derecho de voto múltiple ${ }^{11}$.

2) Acciones ordinarias o diferidas (ordinary or deferred shares) que reciben dividendos solamente después del primer reparto efectuado a las acciones privilegiadas ${ }^{12}$.

11 Ley de 21 de diciembre de 1908 , art. 45 y 69. 
3) Acciones de industria (founder shares) que incluyen los bonos del promotor y fundador del derecho continental ${ }^{13}$.

A partir de ese momento, "(...) la posibilidad de crear clases de acciones siempre se ha contemplado en la legislación mercantil británica" (Gower 1997: 48-53). La Ley de Sociedades vigente (cuerpo formado por The Companies Act 1985 y The Companies Act 2006) admite la emisión de acciones con derechos diversos, tanto de carácter patrimonial como de naturaleza administrativa. El Derecho británico admite la creación de acciones con derechos privilegiados (preferred shares), acciones postergadas (deferred shares), acciones de fundador (founder's shares), acciones de oro (golden shares), acciones convertibles (convertible shares), acciones rescatables (reedemable shares), acciones sin voto (non voting shares) y otras clases de acciones caracterizadas por una diversa atribución del derecho de voto (contingent voting, disproportionale voting, voting debt securities y ordinary non voting shares). La emisión de acciones postergadas no es frecuente y generalizada en ningún país del mundo, "(...) pero si en alguna legislación ha tenido una relativa importancia, esa es la británica" (Pennington 1985: 238).

Por su parte, la figura de las acciones privilegiadas se introdujo en Estados Unidos ${ }^{14}$ por medio de una empresa ferroviaria. The Baltimore and Ohio Railroad Company fue la primera compañía que autorizó en sus estatutos sociales la emisión de acciones privilegiadas en 1836. Esa época fue el momento de más éxito, existiendo numerosas emisiones, sobre todo "(...) entre las empresas de ferrocarriles y de provisión de servicios públicos" (Ripley 1912: 37-43; Evans 1931: 56-62; Depenbrock 1975: 21).

En Estados Unidos, la Common Law y la jurisprudencia sancionan, desde un principio y con carácter general, "(...) una absoluta libertad de pactos sociales" (Merrick 1937: 27-44). Junto a las acciones ordinarias (common stocks), pueden existir acciones privilegiadas (preferred stocks) que atribuyen privilegios de orden económico, acciones garantizadas (guaranted stocks), acciones postergadas (deferred stocks), acciones

12 Ley de 21 de diciembre de 1908, art. 45-56.

13 Ley de 21 de diciembre de 1908, art. 37 y 38.

14 La característica fundamental de este primer momento, hecho que aun continúa en la actualidad, es que existen varias clases diferentes, con distinta regulación en cada uno de los Estados que conforman la Unión. 
convertibles (convertible stocks) ${ }^{15}$, acciones rescatables (redemption stocks), acciones sin voto (non voting stocks) y acciones sin valor nominal (stocks without par value) ${ }^{16}$.

Mientras que las sociedades de la Europa continental están financiadas mucho más por obligaciones que por acciones, las empresas ferroviarias estadounidenses están financiadas casi a partes iguales entre acciones y empréstitos. Este hecho es justificado al principio del siglo XX de la siguiente manera: "(...) muchas compañías ferroviarias hicieron entregas de acciones gratuitas o liberadas a los fundadores, contratistas o primeros accionistas, y de la que se distribuyeron luego acciones de dividendo" (Maristany 1906: 55).

Las acciones privilegiadas han sido utilizadas frecuentemente en Estados Unidos como mecanismo de holdings financieros (trust) en compañías de ferrocarriles que, saneadas bajo la Bankruptcy $A c t^{17}$, recurren a estas acciones para estructurar su nueva dotación de capital, y en la reorganización de servicios públicos para rembolsar obligaciones que habían sido fallidas.

El Derecho estadounidense, y el mercado financiero que regula, presentan dos peculiaridades respecto al resto de las legislaciones y mercados. De un lado, posee una gran cantidad de acciones postergadas o de fundador suscritas por los promotores, en parte por razones de índole financiera, y en parte por publicidad, puesto que su suscripción indicaba confianza en la empresa que se promocionaba. De otro lado, en el Derecho estadounidense, el derecho de voto nunca se ha considerado esencial, por lo que nada se opone al reconocimiento de acciones de voto plural o privadas del derecho de voto. En el Derecho estadounidense, el recurso de las acciones sin voto (non voting stock) se introduce con una absoluta libertad de configuración; "(...) esta flexibilidad, frente a la rigidez continental, ha hecho que sea en Estados Unidos donde mayor éxito han tenido las acciones sin voto" (Bergerman 1928: 445-448; Dood y Baker 1951: 301; Levine 1976: 460; Pennington 1985: 225; Farrar 1991: 221).

15 El art. 6.01 Revised Model Business Corporation Act (RMBCA) contempla la posibilidad de que los estatutos autoricen la emisión de una o más clases de acciones que puedan convertirse en acciones rescatables. También aparece esta posibilidad en art. 512 New York Business Corporation Law y art. 151.b Delaware General Corporation Law.

16 Art. 6.02 RMBCA y art. 151.a Delaware General Corporation Law.

17 http://statutes.agc.gov.sg/non_version/cgi-bin/cgi_retrieve.pl?actno=REVED-20. 


\subsection{Derecho Germánico}

El Derecho positivo de las sociedades por acciones de los países germánicos, al contrario que los países anglosajones, ha dispuesto "(...) un sistema cerrado de clases de acciones" (Campuzano 2000: 55), en el que las categorías de acciones posibles para poder ser emitidos son un número predeterminado y escaso de categorías utilizables por el emisor, que son tipificadas normativamente ${ }^{18}$.

En el ámbito del derecho continental europeo, el siglo XIX marca el inicio del reconocimiento legal de las clases de acciones, movimiento en el que es pionero el Derecho alemán. Desde 1840, se emiten en Alemania acciones prioritarias (Prioritätsaktien), precursoras de las acciones privilegiadas (Vorzugsaktien).

Los autores alemanes identifican que la creación de estos tipos de acciones tiene su origen en las necesidades financieras de las sociedades de ferrocarriles en la época del auge del tráfico ferroviario (Bekker 1871: 712; Auerbach 1873: 77; Zöllner 1984: 223; Siebel 1997: 642), al igual que en Estados Unidos. Para regular las sociedades por acciones se publicó la Ley prusiana de sociedades por acciones de 8 de noviembre de 1843. Desde la década de los años cuarenta del siglo XIX, las necesidades económicas de las compañías de ferrocarriles hicieron que comenzasen a emitir acciones prioritarias (Prioritätsaktien), por lo que se puede decir que este tipo de sociedades son las que primero utilizaron las categorías de acciones para financiarse ${ }^{19}$.

Las Prioritätsaktien se regulan por primera vez en la Aktiennovelle de 18 de julio de 1884, lo que supone que fue el primer Derecho continental europeo en regular la figura de las clases de acciones. La Aktiennovelle permite la creación de acciones prioritarias en el ámbito de los derechos patrimoniales y prohíbe las diferencias sobre los derechos políticos ${ }^{20}$.

18 A este sistema cerrado se le denomina "principio de tipicidad", concepto según el cual no se pueden crear títulos diversos de los tipificados por el legislador.

19 La norma concreta que regulaba, en ese momento, las necesidades financieras de las sociedades dedicadas a la explotación del ferrocarril era la Ley de ferrocarriles prusiana de 3 de noviembre de 1838 . Ninguna de las dos leyes recogían la posibilidad de emitir acciones prioritarias (Prioritätsaktien), pero a su amparo las empresas de ferrocarriles las emitían.

20 La Aktiennovelle de 11 de julio de 1870 había establecido que el derecho de voto constituía un derecho mínimo para todo accionista, debiendo ser éste idéntico para todos los socios. Esto supuso que cuando la Aktiennovelle de 18 de julio de 1884, reguló las categorías de acciones con las Prioritätsaktien, éstas podían tener privilegios en el reparto de ganancias y en el reparto de la cuota de liquidación, pero no en los derechos políticos. 
Este reconocimiento se afianza en el Handelsgesetzbuch (HGB) de 10 de mayo de 1897. El Código de Comercio alemán de 1897 regula las acciones privilegiadas en los §§ 185 y 252. El § 185 de HGB autoriza la creación de derechos diferentes en cada clase de acciones, lo que supone la aparición de las acciones privilegiadas (Vorzugsaktien) ${ }^{21}$. Asimismo, el § 252 de HGB, a diferencia de lo que sucedía en la Aktiennovelle de 1884, permite la creación de acciones de voto plural (Mehrstimmrechtsaktien) ${ }^{22}$, aunque no es posible la emisión de acciones sin voto (Aktien ohne Stimmrecht).

Por otro lado, la práctica alemana de los negocios instauró el bono de disfrute como un mecanismo para compensar financieramente las acciones que se amortizaban por el nominal; la figura fue definida por la práctica como un crédito participativo que no incorporaba el voto y que se representaba en un título (Genusschein). Aunque esta compensación era el propósito inicial de esta figura, posteriormente, se utilizó para los más diversos propósitos: como bono de disfrute con ocasión de amortización de acciones, como mecanismo para remunerar a los fundadores, como instrumento para retribuir participativamente a los trabajadores y directivos o como técnica financiera de fortalecimiento de recursos propios. Las emisiones de Genusschein se iniciaron en las sociedades concesionarias de ferrocarril, aunque posteriormente se amplió su utilización a un gran número de sectores.

\subsection{Derecho Romano}

El Derecho latino, en el que se encuentra España, se analiza por medio de una revisión histórica de los contenidos establecidos en las legislaciones mercantiles francesas e italianas al respecto.

Inspiradas en la legislación alemana, las Leyes francesas de 9 de julio de 1902, 16 de noviembre de 1903 y 22 de noviembre de 1913 modificaron el Código de Comercio y autorizaron la emisión de acciones que confirieran privilegios a sus titulares, salvo que los estatutos lo prohibieran directa y expresamente.

21 El § 185 de HGB señalaba que "El Contrato Social podrá fijar determinados derechos para ciertas acciones, especialmente en lo que se refiere al reparto de ganancias (...)".

22 El $\$ 252$ Inc. $2^{\circ}$ de HGB establece que "Si se emitieran varias categorías de acciones, el contrato social podrá determinar la importancia y extensión del voto para cada clase". 
Con su reconocimiento, se va a producir el afianzamiento de las acciones que atribuyen ventajas patrimoniales a sus titulares, pero, también, la progresiva regresión de las acciones que reconocen privilegios sobre el derecho de voto. Durante los años 1925 y 1926, con la caída del franco, se produce una avalancha de acciones de voto plural (Danos 1922: 26-27, 31-34; Thaller 1930: 380; Hamel, Lagaboe et Jauffret 1980: 242), hasta que la Ley de 26 de abril de 1930 prohibió la emisión de nuevas acciones de voto plural.

La Ley de 13 de noviembre de 1933 prohíbe la existencia de acciones que impliquen una desproporción entre poder de voto y valor nominal. La Ley de 26 de junio de 1957 introduce los certificats pétrolier, valores mobiliarios negociables que recogen todos los derechos inherentes a las acciones, salvo el de voto. La Ley 66-537 de 24 de julio de 1966 de sociedades comerciales mantiene la situación anterior: se admite de forma generalizada la diversidad sobre derechos económicos del socio, mientras que el derecho de voto sólo puede, excepcionalmente, atribuirse en medida distinta a acciones nominativas ${ }^{23}$ o suprimirse a través de los certificats pétrolier, aunque nunca por medio de acciones.

Las acciones sin voto (actions á dividende prioritaire sans droit de vote) no se admiten con carácter general en el Derecho francés hasta la Ley de 13 de julio de 1978 relativa a la "orientación al ahorro a la financiación de empresas" (Ley Monroy), cuyo régimen fue flexibilizado en 1983 por la Ley de 3 de enero de desarrollo de inversiones y protección del ahorro (arts. 269.1-269.9 Loi sur les Sociétés Commerciales). Los primitivos certificats pétroliers evolucionan, de un lado, en las actions á dividende prioritaire sans droit de vote y de otra parte, en los certificats d'investissement et de droit de vote.

La Loi Delors de 3 de enero de 1983 sobre el "desarrollo de las inversiones y la protección del ahorro" (Ley Delors) prevé dos nuevas posibilidades de financiación ofrecidas a las empresas por acciones, sin exigir su pertenencia al sector público: los certificats d'ínvestissement représentatifs des droits pecuniaires y los titres participatifs. Estos certificados, similares a las acciones, se configuran como un producto financiero creado a partir del fraccionamiento de la acción en dos certificats pétrolier que se crean simultáneamente. Los certificats d'ínvestissement représentatifs des droits pecuniaires atribuyen los derechos económicos

23 Arts. 174-176 Loi sur les Sociétés Commerciales. 
de la acción que, para estimular su suscripción, pueden incorporar dividendos privilegiados. Los certificats de droit de vote representatifs des autres droits atribuyen el resto de los derechos en las asambleas generales de accionistas. Estos títulos son nominativos y no negociables, y representan los derechos no económicos atribuidos a la acción. La emisión de estos certificados resulta especialmente interesante para la sociedad emisora, porque le permite aumentar sus fondos sin modificar el equilibrio de poderes.

La última reforma de la legislación sobre valores mobiliarios es la realizada en la Ordonnance $n^{\circ}$ 2004-604 du 24 juin 2004 portant réforme du régime des valeurs mobilières. Esta legislación refunde la mayoría de las figuras de híbrido de capital existentes en un nuevo instrumento financiero. De esta forma, a partir de la emisión de esta Ley, no podrán emitirse las antiguas figuras: (a) préstamos participativos legalmente subordinados (prêts participatifs), (b) certificat d'investissement, (c) certificat de droit de vote y (d) actions à dividende prioritaire. El nuevo instrumento financiero híbrido creado para sustituir a todas las anteriores, son las actions préférence.

Por su parte, las primeras emisiones de acciones privilegiadas, realizadas por empresas italianas, se llevaron a cabo en el año 1884 (Gasperoni 1950: 162).

Tras la reforma de 1942, el Codice Civile italiano admite la posibilidad de crear clases de acciones con un contenido diverso, no sólo en el ámbito de los derechos patrimoniales del accionista, sino también, aunque con muchas más cautelas, en el plano de los derechos administrativos.

El Código Civil italiano opta por prohibir la emisión de nuevas acciones de voto plural (Codice Civile, art. 2351.2). Por el contrario, se introducen en el Código Civil las acciones de voto limitado. Esta particular clase de acciones, privilegiadas en derechos patrimoniales pero con un derecho de voto limitado, se considera un medio de financiación contrapuesto a las acciones ordinarias con características de un instrumento de control. Su reconocimiento se justifica por la constatación de que, en especial en las sociedades de grandes dimensiones, algunos accionistas están desinteresados de la gestión social. Por ello parece oportuno crear clases, sin derecho de voto en las contingencias ordinarias de la vida social, pero que lo conservan en la adopción de decisiones más importantes objeto de deliberación por la asamblea extraordinaria. Esta pérdida 
parcial del derecho de voto se contrarresta con el reconocimiento de algunas ventajas patrimoniales.

Posteriormente, el Testo unico delle disposizioni in materia di intermediazone finanziaria, al sensi degli articoli 8 e 21 della legge 6 febbraio 1996 (Decreto Legislativo [Dlgs] de 24 febrero de 1998, $\mathrm{n}^{\circ}$ 58) introdujo cambios significativos en la disciplina de las sociedades cotizadas, incorporando un régimen propio, y diferenciado, de las sociedades no cotizadas, para las sociedades con acciones cotizadas en el mercado. El Dlgs 24-2-2003 permite a la sociedad anónima recurrir a una tipología amplia de instrumentos financieros, ya no restringidos al binomio accionesobligaciones, sino extendida a las acciones sin voto, a las acciones sin voto limitado a asuntos determinados hasta un máximo o de forma escalonada, a las acciones con derecho de voto subordinado, a las acciones con derechos relacionados con la actividad de un determinado sector y a los instrumentos financieros para la asignación de obras y servicios ${ }^{24}$.

\section{ACCIONES PRIVILEGIADAS EN EL DERECHO ESPAÑOL}

La indefinición del Código de Comercio de 1885 en materia de sociedades anónimas generó críticas que incidieron en la ineludible necesidad de su modificación. En este contexto surge el Proyecto de Reforma de 19 de agosto de 1926, que permite emitir acciones privilegiadas en los derechos económicos del socio, siempre que se respeten cuatro límites. En primer lugar, la validez de la emisión se condiciona a la observancia de las formalidades establecidas para la reforma de la constitución social. En segundo lugar, el privilegio reconocido a los titulares de acciones preferentes no puede suponer la totalidad de los beneficios. En tercer lugar, no puede suprimirse el derecho de fiscalización inherente a la cualidad de socio que tengan los titulares de acciones ordinarias. Por último, el legislador admite la creación de clases de acciones en el ámbito de los derechos patrimoniales, pero rechaza la diversidad en el plano de los derechos políticos incluido el derecho de voto ${ }^{25}$.

2349.2; art. 2351.

24 Decreto Legislativo [Dlgs] de 24 febrero de 1998, $\mathrm{n}^{\circ}$ 58, art. 2346.6, art.

25 El Proyecto de reforma de 1926 rechaza la introducción de desigualdades en la atribución de derechos políticos del socio, y más en concreto, del derecho de voto. Según el texto, el derecho de voto posee carácter esencial, de modo que no sólo debe concederse a todos los accionistas, sino que, además, ha de atribuirse en igual medida a todos ellos. La declaración de igualdad de voto de las acciones, cualquiera que sea su denominación y clase, supone la prohibición de emitir acciones sin voto y acciones de voto plural. 
Más adelante, la Ley de Sociedades Anónimas (LSA) de 17 de julio de 1951 trata de manera específica la emisión de acciones que atribuyan derechos diversos. Las características fundamentales de este texto legal aparecen recogidas en tres aspectos: la equivalencia entre clases y series, el principio de igualdad de derechos y, por último, el principio de proporcionalidad entre el capital y el derecho de voto.

La LSA de 1951 realiza una equivalencia entre los conceptos clase y serie. Esta sinonimia quedará claramente eliminada en el Texto Refundido de 1989.

El Preámbulo II de la LSA 1951 establece la conveniencia de mantener el principio de igualdad de derechos entre los accionistas, "... siempre que se trate de acciones de la misma clase o serie...". Por primera vez el legislador introduce en el ordenamiento español el concepto de clase o serie como conjunto de acciones agrupadas en función de un contenido de derechos idéntico. Dentro de la misma clase o serie debe respetarse el principio de igualdad de derechos de las acciones. En estos términos se manifiesta el artículo 37 de la Ley al establecer que "(...) las acciones de la misma serie o clase serán de igual valor y conferirán los mismos derechos".

La LSA de 1951 consagra el respeto al principio de proporcionalidad entre el capital de la acción y el derecho de voto. Ello supone que la LSA se decanta por admitir la creación de clases de acciones en el ámbito de los derechos patrimoniales del accionista, pero rechaza la diversidad en el plano de los derechos políticos del socio y, específicamente, en cuanto al derecho de voto. El derecho de voto se configura "... como un derecho esencial" que debe atribuirse al accionista de forma proporcional. Con ello se cierra el paso, por un lado, al reconocimiento de acciones desprovistas de derecho de voto o con voto limitado, y por el otro, la emisión de voto plural. La limitación de derecho de voto fue puesta en duda doctrinalmente porque en esa época la emisión de acciones sin voto o con voto limitado empieza a admitirse en el derecho comparado. Asimismo, la LSA rechaza expresamente la emisión de acciones de voto plural. El artículo 38 de la LSA prohíbe la creación de acciones de voto plural basándose en la correlación que debe existir entre el valor nominal de cada acción y el capital social. La Exposición de Motivos de la LSA establece que "... el respeto al principio de la proporcionalidad conduce (...) a la supresión de las acciones de voto plural". La imposibilidad de utilizar esta figura puede tener su origen en 
la prohibición de la emisión de acciones de voto plural en la mayoría de las legislaciones de los países europeos continentales.

El Texto Refundido de la Ley de Sociedades Anónimas (TRLSA), aprobado por R.D. Legislativo 1564/1989, de 22 de diciembre, desarrolla la regulación de las clases de acciones en los artículos 9, 22, 24, 49, 90, 91, 92, 105 y 244.2. Por su parte, las acciones privilegiadas son regladas en el artículo 53 del citado texto legal. Las aportaciones del TRLSA al fomento de las clases de acciones son, fundamentalmente, tres: diferenciación entre clases y series ${ }^{26}$, desarrollo de limitaciones generales para el establecimiento de clases con privilegio sobre derechos patrimoniales $^{27}$, y, por último, la inclusión, por primera vez, de las acciones $\sin$ voto $^{28}$.

La Reforma del TRLSA, realizada en la D.A. $15^{\mathrm{a}}$ de la Ley $37 / 1998$, de 16 de noviembre, de Reforma de la Ley 24/1998, de 28 de julio, del Mercado de Valores (LRLMV) establece tres aportaciones al fomento de las clases de acciones: desarrollo detallado de las acciones con privilegios sobre derechos patrimoniales, modificación en el régimen de las acciones sin voto $\mathrm{y}$, por último, inclusión, por primera vez, de las acciones rescatables ${ }^{29}$.

26 El artículo 49, denominado "clases y series de acciones", establece que: "1. Las acciones pueden otorgar derechos diferentes, constituyendo una misma clase aquéllas que tengan el mismo contenido de derechos. 2. Cuando dentro de una clase se constituyan varias series de acciones, todas las que integren una serie deberá tener igual valor nominal".

27 En la LSA (art. 38) se consideraba ilícita la creación de acciones de voto plural, sin embargo, no se establecían criterios generales para la emisión de clases de acciones con privilegio sobre derechos patrimoniales. El artículo 50 del TRLSA, denominado "acciones privilegiadas", establece que "1. Para la creación de acciones que confieran algún privilegio frente a las ordinarias, habrán de observarse las formalidades prescritas para la modificación de estatutos. 2. No es válida la creación de acciones con derecho a percibir un interés, cualquiera que sea la forma de su determinación, ni la de aquellas que de forma directa o indirecta alteren la proporcionalidad entre el valor nominal de la acción y el derecho de voto o el derecho de suscripción preferente". En el articulado existen tres prohibiciones generales: concesión de un interés, ruptura de la proporcionalidad entre el valor nominal de la acción y el derecho de voto, y derogación del derecho de suscripción preferente.

28 El TRLSA regula, por primera vez, las acciones sin voto. Una sociedad anónima $y$, por extensión, una sociedad comanditaria por acciones, puede emitir acciones sin voto conforme a lo establecido en los artículos 90-92 TRLSA. Con su reconocimiento se acoge la tendencia general en otros ordenamientos favorable a la emisión de acciones sin voto bajo determinadas condiciones e, implícitamente, se deroga el principio de proporcionalidad entre la extensión del derecho de voto atribuido por las acciones y el capital representado por ellas.

29 Utilizamos, la denominación rescatables, por ser la incluida en la legislación española, aunque proponemos la utilización del término acciones recuperables para designar esa figura. Zubiri (2000: 122) también aboga por el término recuperable, entre otras cosas basándose en el significado lingüístico, ya que "(...) recuperable es que el legislador ha querido legislar". La LRLMV introduce una nueva Sección, la Sexta, en el Capítulo IV que, bajo el epígrafe «De las acciones 


\section{ESTUDIO EMPÍRICO: ACCIONES PRIVILEGIADAS EN COMPAÑIIAS ESPAÑOLAS RELACIONADAS CON EL FERROCARRIL}

Del conjunto de empresas relacionadas con el ferrocarril en España, sólo diez han emitido clases de acciones diferentes a las acciones ordinarias. Cuatro sociedades emitieron acciones privilegiadas, cinco empresas emitieron acciones preferentes y una compañía emitió acciones rescatables.

La "Compañía de los Caminos de Hierro del Norte de España" emitió el 22 de julio de 1918 acciones al portador con un interés fijo del $3 \%$ sobre el valor nominal. Como el valor nominal era de 500 pesetas, el interés anual era de 15 pesetas (3\%500).

La empresa barcelonesa "Construcciones y Ferrocarriles S.A." realizó, el 7 de marzo de 1919, un aumento de capital de 4.000 acciones de 500 pesetas de valor nominal, 2.000 de ellas ordinarias y las otras 2.000 privilegiadas.

La "Compañía del Ferrocarril de Madrid a Aragón" utilizaba para financiarse obligaciones simples y acciones privilegiadas. La operación más novedosa es que en el año 1933 realizó un canje de obligaciones por acciones privilegiadas ${ }^{30}$.

\footnotetext{
rescatables», regula esta clase de acciones en los artículos 92 bis y 92 ter. En el Derecho español, las acciones rescatables se contemplaban en el Anteproyecto de la Comisión General de Codificación, de 17 de junio de 1987 (art. 47.1 y ss.), aunque no se recogieron en el texto definitivo del TRLSA. En estos preceptos se fijan las condiciones para su emisión y amortización, aunque no se incorpora ninguna exigencia en cuanto a los derechos que pueden atribuir estas acciones. Ello supone que pueden existir, en primer lugar, acciones rescatables que constituyan una clase, exclusivamente, por la diversidad en el derecho a conservar la condición de socio. En segundo lugar, pueden existir acciones rescatables que atribuyan en forma diversa otros derechos (voto, beneficios y cuota de liquidación) y a las que, por tanto, resultarán aplicables las disposiciones previstas en materia de dividendos preferentes y de acciones sin voto.

30 "En ejecución de lo establecido en la cláusula 5.a del Convenio aprobado por los señores Obligacionistas en las Juntas generales de las Asociaciones Civiles de Obligacionistas de Madrid a-Vaciamadrid y Arganda y de Arganda a Colmenar, con ramal de Morata a Orusco y de Orusco a Alocén, celebradas los días 20 de diciembre de 1932 y 7 de enero de 1933, respectivamente y sancionado por auto del Juzgado de 1.a Instancia número 13 de Madrid, fecha 14 de febrero de 1933 , el Consejo de Administración de esta Compañía ha acordado llevar a efecto el reparto, entre los tenedores de las Obligaciones citadas, de las 3.182 acciones privilegiadas cedidas gratuitamente por un grupo de accionistas, con dicho objeto. La entrega de los títulos de las acciones privilegiadas, a razón de una por cada diez Obligaciones de la misma serie, despreciando las fracciones, se hará mediante presentación de los correspondientes títulos bajo factura en el Banco Internacional de Industria y Comercio, de Madrid y sus Sucursales; en el Banco Urquijo, de Madrid y sus Sucursales; en la Banca Marsans, de Barcelona; en el Banco de Valencia, de Valencia y sus Sucursales, y en las oficinas de la Compañía, Estación del Niño Jesús", a partir del día 1 de marzo de 1934 (La Vanguardia Española, 14 de febrero de 1934, p. 14).
} 
La Société Générale de Tramways de Madrid et d'Espagne (SGTME) fue una sociedad belga, con domicilio en Bruselas. La SGTME se constituyó en 1886 y se centrará en la explotación de los Tranvías del Norte de Madrid. Su capital inicial estaba formado por 10.000 acciones ordinarias (sin valor nominal) y otras tantas privilegiadas, cada una de estas últimas con un valor inicial de 250 francos; en 1906 ambas quedaron sin valor nominal. Los principales capitalistas fueron Barbanson, Bourson, Dansette, Otlet y Peemans, que aportaron, a cambio de 9.500 acciones privilegiadas y otras tantas ordinarias, 5.000 acciones de Tranvías del Norte de Madrid. Las aportaciones no dinerarias de trenes y tranvías era una operación, bastante frecuente entre empresas de servicios públicos de la época.

La "Compañía General de Ferrocarriles Catalanes, S.A." (CGFC) se fundó en Barcelona el 14 de julio de 1919, con un capital social de 15 millones de pesetas repartido en 30.000 acciones. La empresa estuvo en funcionamiento hasta 1977. Dicha compañía estaba participaba mayoritariamente por capital belga. Además de comenzar los trabajos en el tramo Martorell-Manresa Alta para unir las diferentes concesiones, fue absorbiendo las diferentes compañías que integraban la red: la Compañía de los Caminos de Hierro del Nordeste de España el 10 de septiembre de 1920, la Compañía del Ferrocarril Central Catalán el 19 de noviembre de 1921, y la línea de ferrocarril minero de vía métrica entre Manresa y Suria, propiedad de la multinacional Solvay, el 16 de octubre de 1922. La Solvay había suscrito íntegramente una ampliación de capital de 10 millones de pesetas realizada por la CGFC en 1921, y su línea fue convertida en ferrocarril secundario de uso público por Real Orden de 6 de mayo de 1924. La Compañía emitió acciones preferentes el 27 de mayo de 1963 con la denominación "Acciones preferentes serie A" y "Acciones preferentes serie B". En total, el capital social de 89.954.500 estaba formado íntegramente por 179.909 acciones al portador: 74.000 acciones ordinarias, 109.303 acciones preferentes de la serie $A$ y 35.303 acciones de la serie B. Las acciones preferentes de la Serie B tienen un derecho a un dividendo no acumulativo del $4 \%$.

La "Compañía de los Ferrocarriles Económicos de Villena a Alcoy y Yecla" estuvo en funcionamiento desde 1909 hasta 1965. La empresa emitió acciones preferentes el 3 de diciembre de 1910. El capital social total, tras su emisión, fue de 13.015 .000 pesetas, constituidas por 27.400 acciones al portador de 475 pesetas de valor nominal. 
La Barcelona Traction Light and Power Company Limited emitió en 1914 acciones preferentes de 100 dólares oro al 7\% no acumulativo ${ }^{31}$.

La empresa "Ferrocarriles de Cataluña S.A." tenía fuertes intereses y capital procedente de Norteamérica relacionados con la electrificación industrial de Cataluña (Riegos y Fuerzas del Ebro S.A.). La sociedad Ferrocarriles de Cataluña S.A. tenía la intención de continuar la línea desde Sarriá a Sabadell y Terrassa. La sociedad fue constituida el 1 de abril de 1912, emitiendo acciones preferentes de 500 pesetas de valor nominal, con un capital de 12 millones de pesetas. A lo largo de la vida de la empresa se realizaron siete aumentos de capital de acciones preferentes de 500 pesetas de valor nominal: el 7 de marzo de 1919, el 1 de mayo de 1941, el 30 de enero de 1943, el 22 de febrero de 1944, el 24 de junio de 1963, el 27 de mayo de 1968, el 14 de abril de 1969 y el 1 de mayo de 1969. El 27 de mayo de 1968, se realizó la mayor ampliación de capital de su historia, al emitir 270.000 acciones preferentes de 500 pesetas de valor nominal. La empresa se encuentra en proceso de liquidación, siendo el último Informe Anual depositado en el Registro Mercantil el del ejercicio contable 1996. Los valores de "Ferrocarriles Cataluña preferente" cotizaron en la Bolsa de Barcelona. Las acciones preferentes tenían un derecho a un dividendo adicional no acumulativo del $5 \%$. Desde que se emitieron las acciones preferentes, los dividendos a cuenta eran diferenciados para las dos clases de $\operatorname{acciones}^{32}$ e incluso algunos

31 El grupo canadiense Barcelona Traction, Light and Power, se constituyó en Toronto en septiembre de 1911. El objetivo de esta empresa era desarrollar en Cataluña el negocio eléctrico a gran escala, aprovechando los recursos hidráulicos del Pirineo. El primer movimiento de la Barcelona Traction, una compañía liderada por el ingeniero norteamericano Fred Stark Pearson, fue la adquisición de la sociedad Tranvías de Barcelona y de la Compañía Barcelonesa de Electricidad. Desde esa sólida posición iniciaron un ambicioso programa de obras hidráulicas en el Prepirineo. La potente central hidroeléctrica de Seròs entró en servicio en 1914. En esa fecha, la Barcelona Traction, conocida popularmente como "La Canadiense", era la séptima empresa de producción eléctrica del mundo, y la mayor de Europa. En 1923 la Barcelona Traction tomó el control de Energía Eléctrica, adquiriendo de este modo una posición casi monopolista en la producción y distribución de electricidad.

32 El primer dividendo a cuenta diferenciado de Ferrocarriles de Cataluña, S.A. se aprobó el 28 de marzo de 1960. Por mediación del Banco Central y del Banco de Santander, en Madrid y Barcelona, se hizo efectivo el siguiente dividendo por el ejercicio de 1959: acciones preferentes 25 pesetas y acciones ordinarias 22,50 pesetas (La Vanguardia Española, Barcelona, 30 de marzo de 1960, p. 8). La segunda se realizó el ejercicio contable siguiente, pues el día 1 de abril de 1961, y por mediación del Banco Central y del Banco de Santander, en Madrid y Barcelona, se hizo efectivo el siguiente dividendo por el ejercicio de 1960: acciones preferentes por importe de 25 pesetas como complemento al dividendo abonado a cuenta y acciones ordinarias por importe de 22,50 pesetas (La Vanguardia Española, Barcelona, 21 de marzo de 1961, p. 10). El tercer dividendo a cuenta diferenciado se acordó el 10 de octubre de 1966 (en Madrid y Barcelona, por mediación del Banco Central y del Banco de Santander); el importe líquido del expresado cupón es de 20 pesetas para las acciones preferentes y 10 pesetas para las ordinarias (La Vanguardia Española, Barcelona, 11 
dividendos a cuenta se entregan sólo a las acciones preferentes y no a las ordinarias $^{33}$.

La Compañía General de Ferrocarriles, S.A. (hoja número 12.859 del Registro Mercantil de Barcelona) que poseía en el pasivo del Balance emisiones de obligaciones hipotecarias realizadas en 1919, 1920, 1922 y 1924, alcanzó un acuerdo con sus acreedores (Decreto aprobatorio del Convenio de saneamiento financiero número 2.968 de 15 de noviembre de 1962, publicado en el B.O.E. el 24 de noviembre de 1962) para resolver su crisis financiera. El saneamiento consistía en involucrar a los obligacionistas en la marcha de la sociedad mediante su conversión en accionistas y mediante su representación en el Consejo de Administración. Para ello se procedió a la supresión de los privilegios de que gozaban las acciones ya existentes que se convirtieron en acciones ordinarias, y a una fortísima ampliación de capital (Expediente de revalorización y reversión de líneas resuelto por el Ministerio de Obras Públicas por Orden de 28 de septiembre de 1960).

En virtud de la ampliación, las nuevas acciones de la Compañía General de Ferrocarriles, S.A. se entregaron a los antiguos obligacionistas en la relación siguiente: por cada dos obligaciones poseídas se entregaron dos nuevas acciones preferentes serie $A$ y una nueva acción preferente serie $B$, todas ellas a entregar enteramente liberadas. Los obligacionistas privilegiados pasaron a convertirse en accionistas privilegiados (titulares de acciones de la serie A con derecho al cobro de un dividendo de hasta el $5 \%$ no acumulativo sobre el producto líquido de cada ejercicio y de la serie $B$ con un segundo privilegio de hasta el $4 \%$ no acumulativo una vez retribuidas las de la serie A prioritaria). Al objeto de asimilar la posición de obligacionistas a la nueva situación en cuanto a la duración del derecho, se les entregaron acciones serie $B$ rescatables: una vez satisfecha la doble atención retributiva privilegiada, debería destinarse el cincuenta por ciento del remanente como mínimo a la amortización de las acciones preferentes serie $B$ por sorteo y a la par, efectuándose dicha amortización por múltiplos de quinientas mil pesetas y destinándose las

de octubre de 1966, p. 12). Otro dividendo diferenciado se hizo efectivo a partir del día 1 de octubre de 1968, en Madrid y Barcelona, por mediación del Banco Central y del Banco de Santander: acciones preferentes, por un importe 20 pesetas y acciones ordinarias, por un importe líquido de 10 pesetas (La Vanguardia Española, Barcelona, 21 de septiembre de 1968, p. 11).

33 El 1 de octubre de 1954, el Consejo de Administración de la compañía acordó repartir a las acciones preferentes un dividendo de un $4 \%$ neto, a cuenta de los beneficios del ejercicio 1954 (La Vanguardia Española, Barcelona, 1 de octubre de 1954, p. 8). 
fracciones inferiores a esta cifra a un fondo para engrosar la amortización del año o años siguientes.

En este apartado hemos analizado la utilización de clases de acciones en las empresas ferroviarias españolas. Una vez realizado el estudio empírico hemos podido obtener cuatro conclusiones fundamentales:

Las empresas de ferrocarriles españolas presentan en algunos casos clases de acciones, pero en ningún caso se han encontrado diferentes series de acciones en una misma empresas ferroviaria.

La utilización de acciones privilegiadas en España es menor que en otros países.

La tercera conclusión obtenida de la comparación del estudio empírico de empresas españolas con el análisis de los mercados internacionales es que la emisión de acciones privilegiadas en España, al contrario de lo que ocurre en muchos países, tiene escasa importancia.

A pesar de que hasta 1998 no estuvieran legisladas las acciones rescatables en España, una empresa ferroviaria emitió este tipo de títulos con anterioridad a esa fecha: la Compañía General de Ferrocarriles. Las finalidades de esta emisión de acciones rescatables son atender a la reestructuración financiera de la compañía convirtiendo en accionistas a parte de los acreedores.

\section{MOTIVACIONES PARA EMITIR CLASES DE ACCIONES}

Una vez constatada la poca utilización de las acciones privilegiadas en España, es necesario indagar para intentar conocer las posibles razones que pueden provocar la poca iniciativa de los emisores españoles a la hora de acudir a una financiación mediante la diferenciación de las clases de acciones. Para ello analizamos las motivaciones para emitir estos títulos a nivel internacional.

Identificamos cinco razones para emitir acciones privilegiadas: defensiva, fiscal, legal, estratégica y financiera.

En primer lugar la emisión de estos títulos puede tener una motivación defensiva. Las clases de acciones pueden configurarse como un procedimiento de defensa de las relaciones de poder preexistentes en la sociedad (Reckkinger 1983: 216). La estratificación del capital en emisiones con diferentes derechos es utilizada, sobre todo en el mercado 
estadounidense, en situaciones en las que una compañía se encuentra ante la necesidad de disponer de una cierta capacidad de maniobra para poder defenderse de supuestas agresiones por parte de terceros, interesados en conseguir posiciones de control a través de maniobras en el mercado financiero (por ejemplo OPAS).

La emisión de clases de acciones también puede tener una motivación fiscal. En algunos países, la inversión en acciones privilegiadas posee una serie de ventajas fiscales respecto a la inversión en acciones ordinarias. Este proceso es observable, sobre todo, en Estados Unidos, donde los dividendos de acciones privilegiadas han estado exentos de impuestos en un $80 \%{ }^{34}$.

La tercera motivación para emitir clases de acciones puede ser legal. Entre las razones de tipo legal destaca la que se produce en la legislación de Estados Unidos, donde las empresas de servicios públicos de electricidad están obligadas a que la deuda no exceda del $60 \%$ de su pasivo (EIA/DOE 2007). Esta situación obliga a las empresas de sectores regulados a utilizar emisiones de acciones, y en muchas ocasiones, las empresas eligen acciones privilegiadas porque son permitidas y se asemejan económicamente a las deudas. En España no existen tales limitaciones sobre la estructura de capital de las empresas eléctricas, sin embargo, sí las hay en el sector de los intermediarios financieros. Los bancos y cajas de ahorros españolas también presentan limitaciones cuantitativas respecto al porcentaje de deuda que debe poseer respecto al total del pasivo. Derivado de este hecho, la utilización de recursos propios con algunas características de deuda está siendo considerado, cada vez más, como un atractivo instrumento de financiación por los intermediarios financieros.

En cuarto lugar, existen razones de tipo estratégico para emitir acciones privilegiadas, ya que éstas pueden ser utilizadas como un método de financiación útil en el caso de encontrarse en tres situaciones: en fusiones (Brealey, Myers and Marus 1996: 363), en la adquisición de una filial, por medio de la emisión de acciones privilegiadas por la sociedad adquirente, para entregárselas a los accionistas de la filial como parte del precio de compra (Houston and Houston 1991: 49) y, por último, en

34 La motivación fiscal para emitir acciones privilegiadas puede ser observada en The Wall Street Journal (1988: 2); Houston and Houston (1991: 49); Collins and Shackelford (1992: 105); Outslay (1992: 125); Brealey, Myers and Marus (1996: 364); White, Sondhi and Dov (1997: 495); Patterson (1997: 137); Ross, Westerfield and Jaffe (1997: 424); Van Horne (1997: 393) e Ingram and Baldwin (1998: 311). 
situaciones en las que la evolución de la empresa es negativa, porque en este caso es preferible emitir acciones privilegiadas en vez de deuda, debido a que el impago de los dividendos de las acciones privilegiadas no puede ser causa para ser declarado en quiebra (Brändel 1992: 247; Ross, Westerfield and Jaffe 1997: 426).

En quinto lugar, y para concluir, la principal causa que motiva a las sociedades internacionales a emitir acciones privilegiadas tiene carácter financiero, ya que su diseño tiene como objetivo hacer más atractiva la emisión de acciones para que los inversores potenciales elijan la opción de invertir en la empresa frente a los títulos de otras entidades. Con la emisión de acciones con derechos y privilegios variados, la compañía puede llegar a una gama mayor de inversores, incidiendo en un ajuste del coste efectivo de los títulos, teniendo en cuenta los condicionantes de mercado y la fiscalidad ${ }^{35}$.

Como instrumento de financiación, las clases de acciones resultan útiles para dos momentos de la evolución de la empresa. Por un lado, permite luchar contra la escasez de disponibilidades financieras (saneamiento); una empresa amenazada por una crisis difícilmente va a conseguir que los potenciales inversores suscriban sus acciones, sin embargo, puede captar nuevos fondos si ofrecen ventajas a los suscriptores. Por el otro, las clases de acciones son un instrumento válido para lograr la expansión de las actividades de la empresa.

En ambos casos, la idoneidad de las clases de acciones como instrumento de financiación pasa por la atribución al inversor de preferencias que incentiven la suscripción, y, a estos efectos, "(...) resultan idóneas tanto las clases de acciones con una diversidad en derechos patrimoniales como en derechos administrativos" (Beltrán 1994: 200). En efecto, para lograr que una sociedad obtenga nuevas aportaciones cuando se encuentra en una situación en la que es difícil atraer a los inversores, pueden emitirse tanto clases de acciones con diferenciación en los derechos patrimoniales (una de ellas son las preferentes) como clases de acciones con diferenciación en otro tipo de derechos (como rescatables o acciones sin voto).

35 La motivación financiera a la hora de emitir clases de acciones puede ser observada en Cremades (1986: 37-38); Campobasso (1993: 225); Ventura (1982: 1.412); Beltrán (1994: 199) y Tapia (1994: 638). 
Las acciones privilegiadas son producto de la ingeniería financiera. Las acciones, como todos los productos y servicios que se pretenden colocar en el mercado financiero por las empresas, son susceptibles de diversificación al objeto de alcanzar mercados con necesidades específicas y susceptibles de políticas de oferta discriminatorias o de segmentación del mercado. Como las preferencias de los inversores no son idénticas, es posible que la segmentación de los mercados permita penetrar de manera más eficiente en aquellos "nichos de mercado" caracterizados por ciertos rasgos diferenciales en cuanto a preferencia o aversión respecto del riesgo, de la liquidez y de la rentabilidad. Es posible que una sociedad coseche un mayor éxito si configura su producto en el mercado de manera atractiva a cierto sector del público-objetivo inversor.

Pues bien, aunque hemos identificado cinco motivaciones ${ }^{36}$ para emitir clases de acciones en el ámbito internacional ${ }^{37}$, las empresas españolas sólo han tenido dos: la estratégica y la financiera ${ }^{38}$. Este hecho podría ser la principal razón que explicara porque las empresas españolas emiten menos clases de acciones que las compañías domiciliadas en otros países.

\section{VENTAJAS DE LAS CLASES DE ACCIONES}

Aunque las empresas ferroviarias españolas tuvieran menos motivaciones que sus iguales en el panorama internacional, no realizar estas emisiones ha impedido aprovechar muchas ventajas que hubieran cambiado su estructura financiera. En este apartado analizaremos las ventajas de las clases de acciones en general, y de cada una de las figuras en particular.

36 La consecución de los objetivos anteriores justifica la mayor parte de las emisiones de clases de acciones, sin embargo, no es necesario que el fin perseguido se encuentre definido explícitamente en la emisión. Una clase de acciones emitida en su origen con una finalidad protectora de las relaciones de poder preexistentes, puede convertirse en un eficaz instrumento de financiación de la sociedad, y viceversa. A esto hay que añadir que no siempre es posible separar radicalmente los objetivos de una emisión de clases de acciones, por el contrario, "(...) cuando una sociedad crea clases de acciones lo habitual es que lo haga atendiendo, simultáneamente, a razones financieras y de protección de las relaciones de poder preexistentes" (Sánchez 1992: 2.498).

37 Por ejemplo, en Estados Unidos se dan las cinco finalidades.

38 La motivación legal sólo es aplicable a los intermediarios financieros españoles. 
Las acciones privilegiadas son un buen medio de financiación para empresas que desean autonomía de los poderes fácticos ya establecidos: acreedores y accionistas ordinarios.

La emisión de privilegiadas para el emisor es que permite flexibilización frente a otras fuentes financieras, como por ejemplo las deudas bancarias y las acciones ordinarias. Con la emisión de rescatables se amplían las posibilidades de financiar la empresa con acciones. Esto concede dos ventajas. Por un lado, proporciona una mayor autonomía del control que pueden ejercer en la empresa los acreedores, fruto de un excesivo endeudamiento. Por el otro, el aumento de financiación en acciones reduciría ( $\mathrm{y}$, por tanto, mejoraría) la ratio de endeudamiento ${ }^{39}$ de la empresa, mejorando los indicadores de solvencia, lo que permite la captación posterior de nueva financiación ajena a menor coste.

Las acciones privilegiadas, al tener naturaleza jurídica de acciones, pueden ser un buen medio para las empresas para cubrir sus niveles de recursos propios frente a los niveles de deudas. La principal ventaja de la emisión de clases de acciones respecto a otras figuras es que pueden configurar las acciones para que tengan las características económicas de una deuda, pero siempre serán acciones a todos los efectos. Esta ventaja podría haber sido muy importante para las empresas ferroviarias que estuvieron muy endeudadas y necesitaron aun más financiación, porque hubieran podido conseguir recursos cuando tenían difícil el acceso a la financiación bancaria, por tener niveles de endeudamiento altos.

La gerencia debe tener en cuenta si la empresa se encuentra en una época de expansión o recesión; en tiempos de recesión es preferible usar una mayor proporción de neto, mientras que en momentos de expansión se puede emplear sin peligro, y con mayor provecho, una mayor proporción de pasivo exigible.

Las acciones privilegiadas presentaban una ventaja superlativa para los tiempos de crisis. La financiación de deudas y empréstitos debe ser remunerada obligatoriamente, tanto si existen beneficios o pérdidas contables en el ejercicio. Por su parte, en España, no se entregan dividendos si existen pérdidas, sólo se puede realizar en los ejercicios contables con beneficios; pero incluso, si la empresa obtiene

39 La ratio de endeudamiento equivale al cociente entre los recursos ajenos y los recursos propios. 
resultados positivos, pero prevee una posible mala situación económica futura, no tiene ninguna obligación legal o mercantil para entregar esos dividendos. De esta forma, la empresa podría no haberse desprendido de unos recursos que pueden ser vitales en un momento posterior ${ }^{40}$.

\subsection{Ventajas de las acciones privilegiadas}

Respecto al caso concreto de las acciones privilegiadas más comunes, las acciones privilegiadas en derechos económicos, pueden tener unas finalidades adicionales. Las acciones con una preferencia en derechos económicos pueden incentivar la suscripción cuando la situación del mercado de capitales no permita una colocación rápida y ventajosa de nuevas acciones ordinarias. Ante la prohibición de emisión de nuevas acciones por debajo del valor nominal, si la cotización bursátil de las acciones es especialmente baja, cerca del valor nominal, sólo es posible una nueva emisión de acciones ligeramente por encima o, incluso, por el valor de cotización. Ello supondría que la sociedad absorbería un capital propio muy caro, porque si la cotización de la emisión sube, los costes reales del capital descienden. Para evitar esto y, a la vez, asegurar una colocación ventajosa en el mercado de acciones con una cotización aceptable, se ofrece como fórmula la acción privilegiada en derechos económicos, "(...) donde el privilegio en derechos económicos funciona como incentivo" (Donaldson 1962: 124-126).

\subsection{Ventajas de las acciones sin voto}

El fundamento para su creación es que en las grandes sociedades anónimas resulta imposible reunir en junta general a todos los socios y, además, se aprecia un creciente desinterés de los pequeños accionistas en la marcha de la gestión social. Las acciones sin derecho de voto dan respuesta a los nuevos intereses de ese sector accionarial.

40 La entrada en vigor de la LRLMV en 1998 rompió esta situación. Las acciones privilegiadas realizadas a partir de su entrada en vigor obligan a la sociedad emisora a repartir dividendos a los titulares en el primer ejercicio en que existan beneficios, lo cual representa una desventaja más. Algunas situaciones pueden desaconsejar a la empresa el reparto de dividendos, aun teniendo beneficios, por ejemplo, cuando exista un desequilibrio entre las masas patrimoniales. La actual legislación española obliga a entregar la remuneración a los titulares de acciones privilegiadas, aunque este hecho suponga comprometer la estabilidad futura de la empresa. En otras legislaciones, como la estadounidense, la entrega de dividendos se puede omitir aun teniendo beneficios, protegiendo la solvencia de la entidad. 
La principal motivación para emitir acciones sin voto es financiera, pues la empresa emisora de estas acciones busca inversores potenciales que le proporcionen los recursos que necesita. Cuando el mercado se encuentra en situación de saturación, por el gran número de alternativas de inversión que ofrece, las empresas emisoras identifican las características de un perfil de accionista denominado "de ahorro", con unas necesidades específicas, y emiten acciones sin voto para absorber sus recursos. Esta idea se basa en que sólo una parte del accionariado (accionistas de control) se interesa por la gestión social, mientras que el resto es atraído únicamente por el rendimiento patrimonial de los títulos (accionistas de ahorro) ${ }^{41}$.

El marketing financiero genera soluciones a problemas del mercado y las empresas que lo componen. Esto ocurre con la doble estructuración de capital (dual capitalization) entendida como la financiación por medio de varios tipos de acciones con diversas características para obtener la mejor estrategia de riesgo y rentabilidad ${ }^{42}$. La doble estructuración de capital responde a la solución eficiente del problema típico de la dispersión del accionariado con los dos extremos de la balanza societaria: por un lado los accionistas de control, y por el otro los accionistas inversores que representan el "capital flotante". De esta forma, la financiación mediante acciones sin voto tiene un fuerte atractivo para los inversores que están dispuestos a cambiar dividendo por voto, porque pueden ser un instrumento fundamental para edificar un determinado equilibrio societario de poderes.

Además de ser derivado de la innovación financiera y del marketing financiero, existen otras situaciones específicas en las que puede ser adecuada la emisión de acciones sin voto: procesos de reorganización empresarial, reconversión o industrialización, conservación del control público de las sociedades estatales y recapitalización sin riesgos de la pérdida de control familiar o grupal. Respecto a esto último, la OPA (Oferta Pública de Adquisición de acciones o takeover bid) es una operación dirigida a la adquisición de un determinado volumen de

41 La motivación inicial de las acciones sin voto parece que es satisfacer las necesidades de los pequeños inversores interesados únicamente por la rentabilidad económica de su inversor, y no tanto por participar en la gestión de la sociedad. No obstante, parte de la doctrina (Kriebel 1963: 175) estima que a quien realmente interesa la existencia de tales acciones es a los grupos de poder de las sociedades emisoras.

42 El concepto de dual capitalization ha sido analizado, entre otros, por Simmons (1987: 106-125) y Gordon (1988: 10). 
acciones, admitidos a negociación en una bolsa de valores, que directa o indirectamente pueden dar derecho a su suscripción o adquisición, para de esta forma, llegar a alcanzar una participación significativa en el capital de una sociedad. La emisión de acciones sin voto es, para la empresa emisora, una garantía de protección frente a una posible OPA futura, porque las acciones sin voto no puedan agruparse para designar a los administradores por el sistema proporcional ${ }^{43}$.

\subsection{Ventajas de utilización de las acciones rescatables}

Una de las razones por las que se utilizaron acciones rescatables en el mercado financiero internacional es porque la financiación con acciones ordinarias presentaba problemas para el emisor. Las ordinarias son, para la empresa emisora, instrumentos que conceden muchos derechos a los titulares, lo que puede pasar factura en tiempos de dificultad, por ser muy cara su posterior reestructuración. Ante esta situación, parece razonable configurar parte del capital con vida temporal y facultades transitorias.

Las acciones rescatables son producto de la ingeniería financiera. Las acciones, como todos los productos y servicios que se pretenden colocar en el mercado por las empresas, son susceptibles de diversificación al objeto de alcanzar mercados con necesidades específicas y susceptibles de políticas de oferta discriminatorias o de segmentación del mercado. Como las preferencias de los inversores no son idénticas, es posible que la segmentación de los mercados permita penetrar de manera más eficiente en aquellos «nichos de mercado" caracterizados por ciertos rasgos diferenciales en cuanto a preferencia o aversión respecto del riesgo, de la liquidez y de la rentabilidad. Es posible que una sociedad coseche un mayor éxito si configura su producto en el mercado de manera atractiva a cierto sector del público-objetivo inversor.

La cláusula de rescate dota al instrumento financiero "acción rescatable" de la versatilidad de las opciones financieras. Cuando el rescate es un derecho del emisor las rescatables tienen una estructura

43 La regulación de las OPAs está diseñada para proteger a los titulares de acciones ordinarias, pero no especifica el tratamiento de las acciones sin voto. Sólo en el caso concreto de las OPAs de exclusión de bolsa, la oferta debe extenderse a todas las acciones. El atractivo de las acciones sin voto es inversamente proporcional a la probabilidad de cambios en la estructura de propiedad. 
análoga a las call options: su emisión permite a la sociedad un margen de flexibilidad en la reestructuración financiera de sus recursos propios. En caso de una fuerte caída de los tipos de interés o de una mejora del "rating de solvencia" del emisor (abaratamiento de las condiciones de financiación), la sociedad puede utilizar el rescate para refinanciarse con la amortización de las rescatables. Cuando el rescate se deja a la voluntad del accionista, las rescatables funcionan de manera análoga a una "put option" lo que incrementa la liquidez del instrumento. Con un determinado precio de rescate establecido, el accionista podrá cobrar un premio de rescate sobre el mercado cuando ejercita el rescate por un precio superior al de cotización.

Las acciones rescatables nacen como instrumento de financiación, pero su emisión no dependerá únicamente de la estructura de la sociedad emisora, sino también de las motivaciones de inversión de los accionistas y de las necesidades de financiación de la empresa emisora.

Las emisiones de acciones rescatables pueden tener diversas razones por las que pueden ser utilizadas: para la reestructuración financiera de su capital, para sanear una compañía o para reorganizar su capital permanente por razones estratégicas. Las estrategias financieras pueden tener dos orientaciones, en parte contrarias: la conversión de capitales propios en capitales ajenos para aprovechar el efecto apalancamiento o la transformación de los acreedores en accionistas. El efecto palanca o apalancamiento (l'effet de levier) explica cómo, en períodos de inflación, la rentabilidad de las compañías podría mejorar (o al menos no empeorar) si las inversiones se financian recurriendo a capitales ajenos más que a capitales propios, y viceversa (Cozian y Viander 1992: 109). Al servicio de esta transición entre períodos inflacionarios y no inflacionarios, entre tasas de interés altas y bajas, podrían situarse aquellas fórmulas de capitalización reversible o con carácter no permanente ${ }^{44}$.

Además, es necesario destacar que las acciones rescatables son instrumentos de financiación con costes inferiores a otras fuentes de financiación temporales, como la emisión de empréstitos.

44 Según Sánchez Andrés (1999: 49) lo pretendido por el legislador español al introducir las rescatables no ha sido otra cosa que "(...) permitir a la sociedad refinanciarse a menor coste cuando descienden los tipos de interés, sin los inconvenientes de recurrir a sucesivas emisiones de deuda, mediante procesos permanentes de ida y vuelta". 
Las acciones rescatables permiten introducir un alto grado de flexibilidad, siendo útiles para hacer frente a las necesidades coyunturales. La creación de unas acciones privilegiadas con un precio de rescate por encima del precio de emisión proporciona flexibilidad a la compañía, ya que sin el establecimiento de una característica de rescate en las acciones privilegiadas la corporación únicamente podría retirar la emisión mediante un método más caro: comprar las acciones en el mercado abierto.

Además de los incentivos y desincentivos generales de los títulos, es necesario realizar un análisis del sujeto que tiene la opción de ejercer el derecho de rescate. La principal ventaja para el emisor de rescatables a opción del emisor ${ }^{45}$ frente a las ordinarias es que, al tener la posibilidad de rescate, permite a la emisora modificar su política financiera en cualquier momento, atendiendo para ello a la evolución que observe en el mercado en cuanto a los costes financieros de la deuda. Además, la posesión de acciones rescatables a opción del emisor permite una refinanciación más barata a través del ejercicio de rescate y de una nueva emisión de acciones.

\section{CONCLUSIONES}

Existen diferencias territoriales en la financiación de las empresas ferroviarias. Las empresas ferroviarias estadounidenses y británicas están financiadas a partes iguales entre acciones y empréstitos, mientras que las sociedades de la Europa continental están financiadas mucho más por obligaciones que por acciones. De la misma forma, también existen diferencias dentro de la clase de empréstitos y de la estructura del capital. En Estados Unidos, casi todas las compañías ferroviarias están financiadas por cuatro tipos de empréstitos: obligaciones hipotecarias, obligaciones diversas, obligaciones cuyo seguro radica únicamente en el beneficio líquido y obligaciones cuya garantía única es el material móvil de las compañías; por su parte, en la Europa continental, normalmente existe un único modelo de obligaciones, bien sea de carácter personal, como en Francia, bien de carácter hipotecario, como en España. El capital social de las empresas ferroviarias en Estados Unidos y el Reino

45 Evidentemente también se puede ampliar estas afirmaciones a las emisiones que tengan derecho de rescate a opción conjunta del emisor e inversor. 
Unido está compuesto por acciones ordinarias y privilegiadas, mientras que el capital en la Europa continental está formado por acciones ordinarias en casi todos los casos; la recurrencia de las privilegiadas, rescatables, preferentes y sin voto en la Europa continental es mucho menor a la del mercado anglosajón.

Las similitudes entre la estructura financiera de las empresas francesas y españolas, y su distinción del modelo anglosajón y germánico, no es casual. La mayoría del capital de las compañías españolas tiene su origen en pudientes familias francesas, y en menor medida belgas, derivado de ello, se importa la forma y los instrumentos de financiación.

Las empresas ferroviarias españolas se han financiado mayoritariamente por medio de empréstitos. Aunque no es lo más común, es posible encontrar ejemplos de empresas relacionadas con el sector ferroviario que emitieron acciones preferentes, privilegiadas y rescatables.

\section{BIBLIOGRAFÍA}

AUERBACH, W. (1873) Das Aktienwesen. Frankfurt: Sauerlander's Verlag.

BEKKER, E.J. (1871) "Beiträge zum Aktienrecht", Beiträge zum Aktienrecht. II. Die innteren Rechtsverhältnisse der Aktiengesellschaften nach dem Handelsgesetzbuch und dem Gesetz vom 11. Juni 1870, Zeitschrift für das Gesamte Handelsrecht (ZGH) 17 (NF 2), S. 379, n 16, 1871.

BeLTRÁn SÁNCHEZ, E. (1994) "Las clases de acciones como instrumento de financiación de las sociedades anónimas". Antonio POLO DíEZ (coord.) Estudios de Derecho Bancario y Bursátil, Homenaje a Evelio Verdera y Tuells, Tomo I. Madrid: La Ley.

Bergerman, M. (1928) "Voting Trusts and Non-Voting Stock", Yale Law Journal, XXXVII, 1927-28, pp. 445-467.

BRÄNDEL, O.C. (1992) Aktiengesetz. GroBkommentar. Berlin: Water de Gruyter.

BREALEY, Richard A.; Stewart C. MYERS and Alan J. MARUS (1996) Fundamentals of Corporate Finance. New York: Mc Graw-Hill.

CAMPOBASSO, G.F. (1993) "Gli strumenti di finanzamiento: le obbligazioni". Il diritto delle Societá per azioni: problemi, esperienze, progetti, a cura di P. Abbadessa e A. Rojo. Milano: Giuffreè, pp. 225-285. 
CAmpuzAno Laguillo, A.B. (2000) Las clases de acciones en la sociedad anónima. Madrid: Civitas.

Collins, Julie H. and Douglas A. SHACKELFORD (1992) "Foreign Tax Credit Limitations and Preferred Stock Issuances", Journal of Accounting Research, 30, Supplement, pp. 103-124.

Companies Act 2006 (2007) Alistair ALCOCK, John BIRDS, Steve GALE (eds.). Bristol: Jordans

CotTon, J. (1995) "Australia: Share Buy-Backs", Company Lawyer, 9, pp. 287-288.

COZIAN, M. and A. VIANDER (1992) Droit des sociétés. Levallois: Francis Lefebvre.

CREMADES, B. (1986) "Aspectos actuales de la financiación de las empresas". La Ley: Revista jurídica española de doctrina, jurisprudencia y bibliografía, 1, pp. 1.186-1.193.

DANOS, G. (1922) Les actions à vote plural. Université de Paris, Faculté de Droit, pp. 26-27.

DaVIES, P.L. (ed.) (1997) Gower's Principles of Modern Company Law. With a contribution from D.D. Prentice. London: Sweet \& Maxwell.

DEPENBROCK, H. (1975) Zur Entwicklung und Bedeutung der Vorzugsaktien in der Aktienrecchten der USA und im deutsche Aktienrecht. Eine vergleichende Undersuchung. Bielefeld, Univ., Fak. f. Rechtswiss., Diss.

DOOD, M. and R.J. BAKER (1951) Cases and Materials on Corporations. Brooklyn: The Foundation Press.

DonaldSON, G. (1962) "In Defence of Preferred Stock", Harvard Business Review, 40, pp. 123-136.

Energy Information Administration/Department of Energy (EIA/DOE) (2007) Pricing Electricity in a Competitive Environment, Background, Modelling Competitive Electricity Pricing [http://www.eia.doe.gov/ emeu/pgem/electric.html, consultado 1/06/2009].

ENGEL, E.; M. ERICKSON and E. MAYDEW (1999) "Debt-Equity Hybrid Securities", Journal of Accounting Research, 2, 37, Autumn, pp. 249-274.

Evans, G.H. (1931) "The Early History of Preferred Stock in the United States, 1850-1878", American Economic Review, 21, March, pp. 43-58.

FARRAR, J.H. (1991) Company Law. London: Butterworths.

GAILLARD. P.E. (1938) Comment éluder la suppression des actions à vote privilégié par la loi de 13 novembre 1933.... Paris: Librairie du "Recueil Sirey". 
GASPERONI, N. (1950) Las Acciones de las Sociedades Mercantiles. Madrid: Editorial Revista de Derecho Privado.

GoRDon, J.N. (1988) "Ties that Bond: Dual Class Common Stock and the Problem of Shareholder Choice", California Law Review, 75, pp. 10-35.

Hamel, J.; G. Lagaboe et A. Jauffret (1980) Droit commercial, I, vol. 2. Paris: Dalloz.

Houston, Arthur L. and Carol O. Houston (1991) "The Changing Use of Preferred Stock", Management Accounting, December, pp. 47-48.

HowelLS, P. and K. BAIN (2002) The Economics of Money, Banking and Finance, 2nd ed. Harlow: Prentice Hall.

INGRAM, Robert W. and B.A. BALDWIN (1998) Financial Accounting. Cincinnati, Ohio: South-Western College Publishing.

KINDLEBERGER, C.P. (1993) A Financial History of Western Europe. Oxford University Press.

KRIEBEL, M. (1963) "Mehr stimmrechtslose Vorzugsaktien?", Die Aktiengessellschaft, pp. 175-195.

KüBLER, F. (1998) Gesellschaftsrecht. Heidelberg: C.F. Müller Verlag.

LAMANDINI, M. (2001) Struttura finanziaria e gobernó nelle societa di capitali. Bologna: Il Mulino.

LEHMAN, K. (1964) Das Recht. Berlin: Geburtstag.

LeVINE, M.L. (1976) Business and the Law. Minnesota: West Pub.

MARISTANY, E. (1906) "Los ferrocarriles americanos", Revista de Obras Públicas, 1.581, 25 de enero, pp. 2-6.

MATTEI, U. (2003) "La riforma del diritto societario italiano. Una nuova ricezione acústica?", Rivista di Diritto Commerciale, I, 615, pp. 616617.

MERRICK, E.J. (1937) "Statutory Developments in Business Corporation Law. 1886-1936", Harvard Law Review, 50, November, pp. 27-59.

MOURGUES, N. (1996) Capitaux propres et quasi fonds propres. Paris: Economica.

OUTSLAY, Edmund (1992) "Discussion of Foreign Tax Credit Limitations and Preferred Stock Issuances", Journal Accounting Research, 30, supplement, pp. 125-130.

PATTERSON, Alan (1997) "Turning Away from Stock", Euromoney, December, 344, p. 137. 
Pennington, Robert R. (1985) Company Law. London: Butterworths.

PeÑAs MOYANO, B. (2007) "Algunas consideraciones en relación al Derecho estadounidense de sociedades por acciones", Revista de Derecho de Sociedades, 28, pp. 240-262.

- (2008) "Las categorías de acciones en el derecho societario alemán: concepto, tipología y tutela de las mismas", Revista de Derecho de Sociedades, 30, pp. 123-162.

PISANO MASSAMORMILE, A. (2003) "Azioni ed altri strumenti finanziari partecipaviti", Rivista delle Societá di Capitali, 48, pp. 1.268-1.315.

POTTIER, A. (1934) Les actions à vote plural. Leur réglementation. Commentaire, critique et formulaire. Loi du 13 novembre 1933. Paris: Dunod.

RECKKINGER, G. (1983) "Vorzugsaktien in der Bundesrepublick", Die Aktiengesellschaft, 15, pp. 216-251.

Revista de Obras Públicas (1906) Balance Ferroviario, $n^{\circ} 1.581,11$ de enero de 1906.

RIPLEY, W.Z. (1912) Railroads: Rates and Regulations. New York: Longmans, Green \& Co.

Ross, Stephen A.; Randolph W. WesterfieLD and Jeffrey F. JAfFE (1997) Corporate Finance. New York: Mc Graw-Hill.

SÁNCHEZ ANDRÉS, A. (1992) "A propósito de un caso de transformación temporal de acciones ordinarias en preferentes sin voto, con opción a recuperarlo", Revista Crítica de Derecho Inmobiliario, 613, pp. 24952499.

- (1999) Sociedad anónima modelo 1988. Reforma (parcial) y crítica (total) de un texto legislativo reciente. Madrid: Mc Graw Hill.

SIEBEL, U.R. (1997) "Vorzugsaktien als hybride finanzierungsform und ihre grenzen", Zeitschrift für das gesamte Handelsrecht und Wirtschaftsrecht, 161, pp. 642-655.

SIMMONS, P.L. (1987) "Dual Class Recapitalization and Shareholders Voting Rights", Columbia Law Review, 87, pp. 106-125.

Tapia HermidA, A.J. (1994) "Instrumentos jurídicos para la financiación de la sociedad de responsabilidad limitada", Revista de Sociedades, extraordinario, pp. 633-648.

TEDdE, P. (1978) "Las Compañías ferroviarias en España (1855-1935)". M. ARTOLA (dir.) Los ferrocarriles en España, 1844-1943. Madrid: Banco de España, vol. II, pp. 9-355. 
ThALler, E. (1930) Traité elementaire de droit commercial. Paris: J. Percerou.

VAN HoRne, J.C. (1997) Financial Management and Policy. New York: Prentice-Hall.

VentuRA, F. (1982) "Il finanziamento delle impresa da parte dei soci", Le societá, 12, 2, pp. 1412-1414.

The Wall Street Journal (1988) 20 de mayo, p. 2.

WHITE, Gerald I.; Ashwin Paul C. SONDHI and Fried Dov (1997) The Analysis and Use of Financial Statements. New York: John Wiley \& Sons.

ZöLLNER, W. (1984) Kolner Kommentar zum Aktiengesetz. München: Einleitungs-Band.

ZUBIRI DE SALINAS, M. (2000) "Las acciones rescatables o recuperables ¿una opción para las sociedades cotizadas?". J.A. GARCíA-CRUCES GONZÁLEZ (coord.) La(s) reforma(s) de la Ley de Sociedades Anónimas. Madrid: Tecnos, pp. 107-134. 